\title{
High accuracy and precision micro injection moulding of thermoplastic elastomers
} micro ring production

\author{
Calaon, Matteo; Tosello, Guido; Elsborg, René; Hansen, Hans Nørgaard
}

Published in:

4M/IWMF2016 Conference

Link to article, DOI:

10.3850/978-981-11-0749-8 730

Publication date:

2016

Link back to DTU Orbit

Citation (APA):

Calaon, M., Tosello, G., Elsborg, R., \& Hansen, H. N. (2016). High accuracy and precision micro injection moulding of thermoplastic elastomers micro ring production. In 4M/IWMF2016 Conference: Proceedings of 11th International Conference on Multi-Material Micro Manufacture (pp. 23-26). Research Publishing Services. https://doi.org/10.3850/978-981-11-0749-8 730

\section{General rights}

Copyright and moral rights for the publications made accessible in the public portal are retained by the authors and/or other copyright owners and it is a condition of accessing publications that users recognise and abide by the legal requirements associated with these rights.

- Users may download and print one copy of any publication from the public portal for the purpose of private study or research.

- You may not further distribute the material or use it for any profit-making activity or commercial gain

- You may freely distribute the URL identifying the publication in the public portal 


\title{
High accuracy and precision micro injection moulding of thermoplastic elastomers micro ring production
}

\author{
M. Calaon ${ }^{1}$, G. Tosello ${ }^{1}$, R. Elsborg${ }^{2}$, H.N. Hansen ${ }^{1}$ \\ ${ }^{1}$ Technical University of Denmark, Department of Mechanical Engineering \\ 2 Ortofon A/S, Nakskov, Denmark
}

\begin{abstract}
The mass-replication nature of the process calls for fast monitoring of process parameters and product geometrical characteristics. In this direction, the present study addresses the possibility to develop a micro manufacturing platform for micro assembly injection moulding with real-time process/product monitoring and metrology. The study represent a new concept yet to be developed with great potential for high precision mass-manufacturing of highly functional 3D multi-material (i.e. including metal/soft polymer) micro components. The activities related to HINMICO project objectives proves the importance of using tool geometries as reference calibrated artefacts to establish effective process technology development and control. The results allow identifying the correct process windows for optimal part quality reducing product dimensional variation in the micrometer dimensional range. The proposed metrological approach enabled to quantify product dimensional variations based on process and tooling capabilities.
\end{abstract}

Keywords: Micro injection moulding, optical metrology, process quality control development.

\section{Introduction}

In recent years, the manufacturing industry and the society as a whole have witnessed a rapid increase in demand and usage of micro-products and microcomponents in many industrial sectors such as electronics, medical, biotechnology and automotive [1][2]. As a result of the current trend towards product miniaturisation, there is a demand for advances in micro-manufacturing technologies and their integration in new manufacturing platforms. The research on the downscaling of the injection moulding has generated a new process technology, micro injection moulding $(\mu \mathrm{IM})[3]$, capable of micro manufacturing on a mass production scale both one-component and multimaterial micro components [4] characterized by multidimensional scale integration, high accuracy with tolerances in the micrometer range [5]. Injection moulding of micro components poses great challenges in terms of quality control of both the manufacturing process and the products itself. Shot sizes down to 100 $\mathrm{mg}$ and even lower than $10 \mathrm{mg}$, dimensional tolerances in the micrometer range and surface roughness in the sub- $\mu \mathrm{m}$ range call for process control systems and metrology solution with very low relative uncertainties $(<0.1-1 \%)$ [6][7]. The mass-replication nature of the process calls for fast monitoring of process parameters and product geometrical characteristics. However, such a micro manufacturing platform does still not exist at present time. In particular, micro insert moulding has been realized for simple geometries and only with rigid thermoplastics, but not with soft polymers such thermoplastic elastomers (TPE). As a result, a micro manufacturing platform for micro assembly injection moulding with real-time process/product monitoring and metrology is a new concept yet to be developed with great potential for high precision mass-manufacturing of highly functional 3D multi-material (i.e. including metal/soft polymer) micro components. HINMICO project activities have been focus towards these directions. The present paper reports about the optimization of the thermoplastic elastomer (TPE) suspension ring micro injection moulding production, as key components for final product functionalities of a high performances phono cartridges. Towards totalquality production a metrological approach identified as a key enabling technology for future real-time process/product quality monitoring was introduced. The present paper discuss the possibility of controlling effects of different process settings on critical product dimensions variation by introducing a geometrical reference as a measurand linking either process variation, tool characteristic/performances with material behaviour during and after $\mu \mathrm{IM}$.

\section{Micro injection moulding of TPE suspension} rings

To evaluate the injection moulded TPE suspension rings a benchmark study was initially carried out to qualitatively characterize the produced suspension rings. Opening experiments were run with process parameters listed in table 1 . The first batch called "data sheet" utilizes the process parameters recommended by the TPE material supplier. The second produced batch called "high" employed temperatures and pressures values levels greater than the recommended one to observe possible effects on rings replication quality which according to literature [8] could improve the filling and replication. Finally the process settings of the "Improved" batch were found as part of an operational optimization process that tried to achieve better filling and smaller to no defects on the produced parts. This optimization was based on manual inspection under an optical microscope.

\subsection{Scanning Electron Microscope inspection.}

From the top view of Fig. 1 the suspension rings looks well formed, with a small weld line. The gate residual mark is small and does not protrude from the 
surface which is important due to the mounting of the suspension ring in the stylus housing. A large defect is present at the circumference of the inner diameter at the weld line position most probably caused by entrapped air pushed against the pin-core.

Table 1: Process parameters for the investigated production batches

\begin{tabular}{|l|c|c|c|}
\hline Process parameters & $\begin{array}{c}\text { Data } \\
\text { Sheet }\end{array}$ & High & Improved \\
\hline \hline Melt Temperature $\left[{ }^{\circ} \mathrm{C}\right]$ & 185 & 200 & 200 \\
\hline Mould Temperature $\left[{ }^{\circ} \mathrm{C}\right]$ & 40 & 60 & 40 \\
\hline Clamping Force $[\mathrm{KN}]$ & 100 & 100 & 30 \\
\hline Injection velocity $[\mathrm{mm} / \mathrm{s}]$ & 120 & 200 & 85 \\
\hline Switch-over Pres. $[\mathrm{bar}]$ & 300 & 750 & 275 \\
\hline
\end{tabular}

From the cross-section it can be seen how there is a misalignment between the pin-core and the ejector tube, which gives a countersink around the centre hole. The internal geometry does not look very well defined especially toward the ejection side. It is also worth noticing that the corner of the outside diameter at the ejection side very well defined with a small rounding compared to internal corner of the cavity. This difference is probably due to the tooling process capability which cannot create perfect $90^{\circ}$ corners on internal geometries. Effect might be enhanced by the relative low injection and holding pressures used to produce this batch.

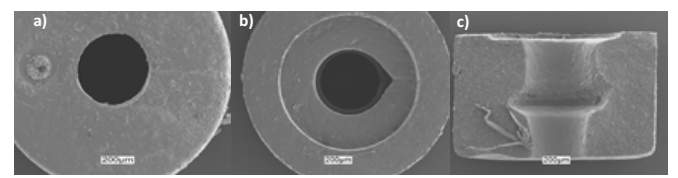

Figure 1: SEM images of parts produced with process parameters called Data Sheet. (a): Top view. (b): Bottom view. (c): Cross sectional view. Scale bars indicate dimension of 200 $\mu \mathrm{m}$.

Continuing analysing the SEM pictures for the batch called High from the top view of Fig. 2, the part looks to be well filled but there is a large defect at end of the deep weld line. The gate also protrudes quite a bit from the surface which cause problems in the later mounting process of the suspension ring.

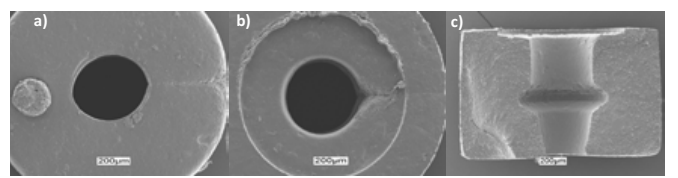

Figure 2: SEM images of parts produced with process parameters called High. (a): Top view. (b): Bottom view. (c): Cross sectional view. Scale bars indicate dimension of $200 \mu \mathrm{m}$.

The bottom view reveals a very large defect due to air entrapment on the circumference of the centre hole. A flash has started to occur in between the pin-core and the inside of the ejector tube, which is possibly due to the increased pressures compared to the data sheet batch. From the cross sectional view it is evident that the internal geometry is more detailed than at the data sheet batch, again this is possibly due to the high pressures which gives better internal replication. However, it can also be seen that the counter sink due to misalignment of the pin-core has increased which could be correlated to the increased pressure. The rounding of the corner of the outer diameter inside the cavity has not improved from the data sheet batch which suggests that the rounding is a consequence of the tooling process.Finally, from the top view of Fig. 3, it can be seen how the parts produced using the improved process settings decrease the depth of the weld line. Similarly, gate mark on the parts is smaller than the one observed for the previous TPE components, produced with different process settings. From the bottom view it is observed that there is a flash along the inner diameter of the ejector tube slightly large than at the data sheet batch but a lot smaller to the one in Fig. 2. The bottom weld line is very small and defect is considerably smaller than at the two previous batches. The internal geometry also looks very well defined, definitely better than the data sheet batch.

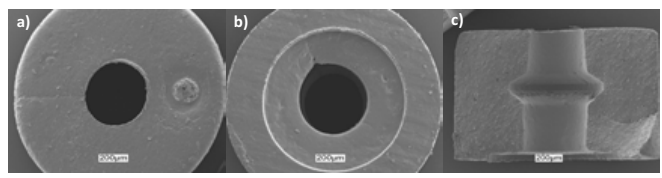

Figure 3: SEM images of parts produced with process parameters called Improved. (a): Top view. (b): Bottom view. (c): Cross sectional view. Scale bars indicate dimension of 200 $\mu \mathrm{m}$.

The qualitative analysis indicated that high pressure and injection speed of the high batch fills the cavity well, but gives problems with defects coursed by entrapped air. Air trap defects were also detected for the data sheet batch indicating that clamping force was the most influencing process parameter affecting the weld lines depth. The correlation between the low clamping force and small weld line defects could be explained by the increased air evacuation at the mould split line as a consequence of the lower clamping force. Although this explanation is plausible more investigations were conducted in order to fully support this relationship.

\subsection{Part mass variation}

One method of monitoring the process variation is to look at the consistency of the part mass. This has been done for the produced TPE suspension rings. 50 parts for each batch were measured and different mass distribution plotted in Fig.4. The smallest mass deviation is obtained using the improved process settings with a low clamping force that allow for better air evacuation compared to other TPE batches as seen in the SEM quality inspection. Results also indicate that it is possible to increase the density of the TPE material by using high processing temperatures and pressures. The density increase influences the damping properties of the material enabling the possibility to produce within the same material compound suspension rings with slightly different damping properties for different types of cartridges.

\subsection{Simulation and experimental comparison}

This investigation aimed at studying the development of weld line formation due to air entrapped during polymer filling of the cavity, Fig. 5. The simulation was capable of predicting the location of the entrapped air that causes the parts defects. Main interest of the numerical product quality optimization was to consequently minimize these defects as much 
as possible in order to ensure uniform damping properties, so that the mounting orientation of the suspension and the vibration direction of the cantilever will not influence the acoustic properties of the finished cartridge. The comparison between simulations and the SEM pictures have shown that all air entrapments occurring at positions that are in contact with mould part lines are reduced to very small weld lines due to the capability of the air to evacuate the cavities through the parting line. At positions where the air cannot escape through any parting lines, defects and surface imperfections develop compromising component functionalities. Generally, the simulations confirmed that bigger weld lines are generated towards the inner cylindrical section of the rings as outlined by the SEM investigation [9].

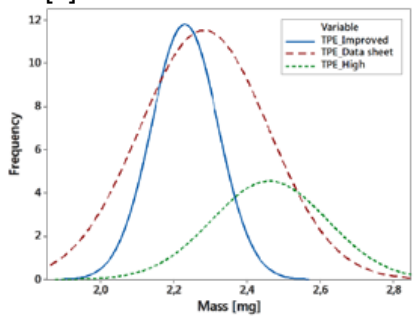

Figure 4: Comparison of part mass distribution for the different production batches. Data sheet batch (avg. value $=2,28 \mathrm{mg}$ $\pm=0,18 \mathrm{mg}$ ). High batch (avg. value $=2,46 \mathrm{mg} \pm 0,16 \mathrm{mg}$ ). Improved batch (avg. value $=2,23 \mathrm{mg} \pm 0,09 \mathrm{mg}$ ).
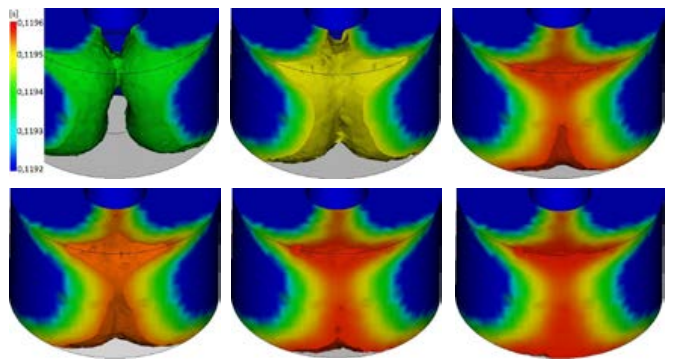

Figure 5: The filling behaviour during the merging of the two flow fronts is broken into six pictures.

\subsection{Dimensional weld line investigation}

Reliable quantification of the weld line is not currently available as output analysis of the numerical software. Dimensional measurements of the weld line depth was performed using a focus variation optical microscope ensuring single acquisitions time lower than production cycle time. Measurement results have shown a direct correlation between tested process parameters and weld line dimensional variation. Larger weld line depth variation was quantified for the rings produced with higher clamping force and injection speed. The results dimensionally quantified the effect of air entrapped into the mould cavity on the final replication quality of the TPE components [10].

\section{Effective product and process control}

A further optimization study was carried out with focus on effective process control based on final part dimensional variation. A statistically designed set of experiments was carried out. The micro injection moulding experiments were executed on WitmannBattenfeld Micro Power 15 with an injection unit consisting of an $\varnothing 14 \mathrm{~mm}$ screw for plasticization and metering combined with a separate $\varnothing 5 \mathrm{~mm}$ injection plunger. Following results obtained in the preliminary studies on which parts defects were minimized as a function of improved final product performances, process parameters, table 2 , were tested during the experimental micro injection moulding phase. 5 repetitions of a full general factorial design $\left(2^{2} \times 3^{2} \times 4\right.$ (cavities) $=144$ experiments) were run.

Table 2: DOE process parameters.

\begin{tabular}{|l|c|}
\hline Process parameters & Values \\
\hline \hline Melt Temperature $\left[{ }^{\circ} \mathrm{C}\right]$ & 210,220 \\
\hline Mould Temperature $\left[{ }^{\circ} \mathrm{C}\right]$ & 30,40 \\
\hline Injection Speed $[\mathrm{mm} / \mathrm{s}]$ & $60,80,100$ \\
\hline Packing pressure $[\mathrm{bar}]$ & $300,400,500$ \\
\hline
\end{tabular}

\subsection{Measurement strategy}

Dimensional quality control of the produced polymer parts was carried out using a focus variation microscope. For each suspension ring three measurements repetitions to quantify the polymer rings inner (ID) and outer (OD) diameter were performed. The two measurands (ID, OD) were extrapolated from each 3D optical surface reconstruction of the produced TPE rings by interpolating inner and outer counter lines with generated circles. The approach ensured measurement robustness and measurement reproducibility. An optical coordinate measuring machine was employed to calibrate mould cavities (outer suspension ring diameter) and pins diameter (inner suspension ring diameter), Fig. 6.



Figure 6: a) Mould plate containing 4 cavities; b) pin entering the cavity during injection moulding production of the suspension ring; c) mould cross section schematic view.

Measuring uncertainty was calculated following ISO 15530-3 [11]. Measurement results are reported in table 3 .

Table 3: Mould cavities/pin calibrated values. Single values indicate average values of 10 different measurements for each inner and outer diameter. $U_{O D}$ and $U_{I D}$ indicate Expanded Uncertainty values in $\mu \mathrm{m}$.

\begin{tabular}{|c|c|c|c|c|}
\hline $\begin{array}{l}\text { Cavity } \\
\text { n. }\end{array}$ & $\begin{array}{l}\text { Outer } \\
\text { Diameter } \\
\text { (OD) [ m] }\end{array}$ & UOD & $\begin{array}{l}\text { Inner } \\
\text { Diameter } \\
\text { (ID) [ } \mathrm{m}]\end{array}$ & $U_{I D}$ \\
\hline Cavity 1 & 1550,4 & \multirow{4}{*}{2,9} & 482,1 & \multirow{4}{*}{2,2} \\
\hline Cavity 2 & 1551,6 & & 482,7 & \\
\hline Cavity 3 & 1549,6 & & 480,8 & \\
\hline Cavity 4 & 1550,1 & & 481,4 & \\
\hline
\end{tabular}

The reference diameter $(\varnothing)$ calculated in Eq. 1 allow to effectively evaluate the different polymer shrinkage directions Fig. $8 \mathrm{~b}$ of inner and outer diameters (ID,OD) in respect of calibrated mould dimensions. Correct shrinkage quantification directly relate to final assembled cartridge (Fig.7) sounds quality. TPE micro rings critical geometries were selected as product quality output indicator based on final product assembly tolerances contains. 


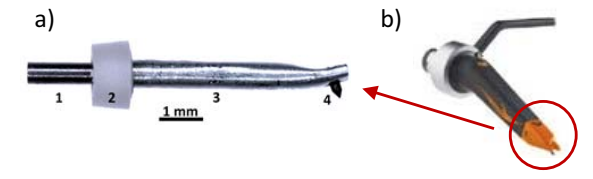

Figure 7: a) Assembled micro components [(1) Magnet (2) TPE suspension ring (3) Aluminium cantilever (4) Diamond tip]; b) Assembled high performance DJ cartridge.

$$
\begin{aligned}
& \text { Tool } \varnothing \text { ref. }=(\mathrm{OD} \text { tool }+ \text { ID tool }) / 2 \\
& \text { ID dev. }=\mid(\mathrm{ID} \mu \mathrm{IM} \text { ring }- \text { Tool } \varnothing \text { ref. }) \mid \\
& \text { OD dev. }=(\mathrm{OD} \mu \mathrm{IM} \text { ring }- \text { Tool } \varnothing \text { ref. })
\end{aligned}
$$
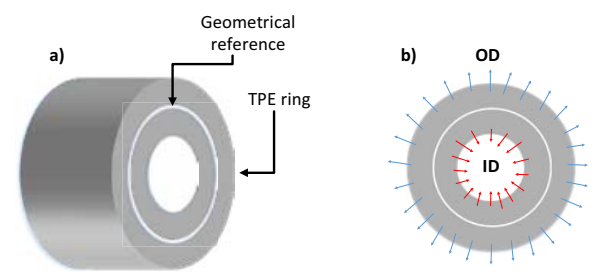

Figure 8: Illustration of TPE rubber ring geometrical reference. a) Side view indicating position of reference measurands to quantify ID and OD polymer behaviour; b) schematic top view of polymer shrinkage behaviour for OD and ID.

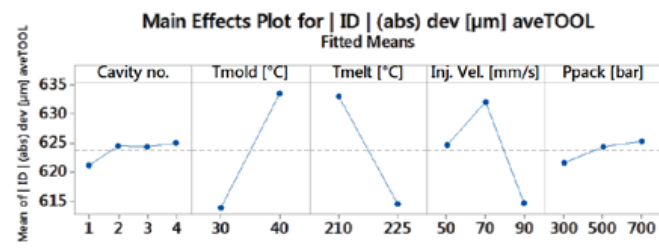

Figure 9: Main effect plot of measured deviation of ID rings in respect of the generated geometrical reference.

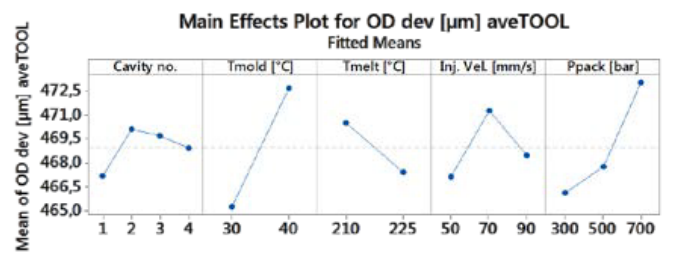

Figure 10: Main effect plot of measured deviation of OD rings in respect of the generated geometrical reference.

The results are presented in Fig. 9 and 10. The absolute internal and outer diameter polymer variation were calculate applying Eq. 2 and 3 respectively. The deviation from the generated geometrical reference system allow for a consistent data analysis procedure. The main effects plots show for the investigated process parameters the same trends for both ID and $\mathrm{OD}$. High process accuracy has been quantified for the different mould cavities. Different cavities show little to no significant effect regarding the different process settings proving high precision tooling capabilities. Homogeneous and symmetrical process conditions were verified for the different cavities of the mould. The proposed metrological approach enabled to quantify product dimensional variations and process capabilities.

\section{Conclusions}

The mass-replication nature of the process calls for fast monitoring of process parameters and product geometrical characteristics. In this direction, the present study reported the development and its production of high accuracy and precision micro injection moulding of thermoplastic elastomers micro rings. The critical factors in $\mu \mathrm{IM}$ process related to injection speed, mold temperature, clamping force, surface replication and simulation accuracy have been presented. The study represent a new concept yet to be developed with great potential for high precision mass-manufacturing of highly functional $3 \mathrm{D}$ multimaterial (i.e. including metal/soft polymer) micro components. The results proves the importance of using tool geometries as reference calibrated artefacts to establish effective product quality control and process monitoring development. In light of the produced results based on dimensional part verification expressed as product variation from a geometrical reference system process and tool accuracy were verified.

\section{Acknowledgements}

This research work was undertaken in the context of HINMICO project ("High throughput integrated technologies for multimaterial functional Micro Components", www.hinmico.eu) HINMICO is a Collaborative Project supported by the European Commission in the 7th Framework Programme (Grant agreement no. 609110).

\section{References}

For a paper citation with one author:

[1] E. B. Brousseau et al., "Some recent advances in multi-material micro- and nanomanufacturing", Int J. Adv. Manuf. Technol., 2010; 47: 2010.

[2] L. Alting et al., Micro Engineering, CIRP Annals, 2003 52(2), 635-657.

[3] M. Heckele, et al., Review on micro molding of thermoplastic polymers, J of Micromech. Microeng., 2004,14(3), 4 pp.

[4] V. Piotter, et al., Multi-component microinjection moulding-trends and developments, 2010, 47, 63-71.

[5] G. Tosello et al., Applications of Dimensional Micro Metrology to the Product and Process Quality Control in Manufacturing of Precision Polymer Micro Components, CIRP Annals, 2009, 58/1, pp 467-472.

[6] B.R. Whiteside et al., In-process monitoring of micro moulding - Assessment of process variation, Int. J. of Polymer Procs., 2005, 162-169.

[7] H.N. Hansen et al., Dimensional Micro and Nano Metrology, CIRP Annals, 2006, 55(2): 721-743.

[8] G. Tosello et al., The COTECH knowledge database: assessment of critical factors in micro moulding, Int. Conf. 4M, 2012, 229-236.

[9] F.B. Hasnaes et al., Investigation of air entrapment and weld line defects in micro injection moulded thermoplastic elastomer micro rings, Int. 4M conf., 2015, 266-267.

[10] F.B. Hasnaes et al., Weld line optimization on thermoplastic elastomer micro injection moulded components using 3D focus variation optical microscopy, euspen int. conf., 2015, 2 pp.

[11] ISO 15530-3: technique for determining the uncertainty of measurement, 2011. 